\title{
Subprime Side Effects in the Federal Funds Market
}

\author{
Daniel L. Thornton
}

$\mathrm{T}$

he recent turmoil in the subprime mortgage market has had implications for the federal funds market. An apparent flight to "safe" investments caused the federal funds rate to behave somewhat differently from what one might expect during a "liquidity crisis." Specifically, in the wake of these developments, the rates on alternative sources of funds for depository institutions rose, while the federal funds rate dropped-falling and remaining below the FOMC's target of 5.25 percent. The funds rate fell without any unusual open market operations (OMOs) or adjustment to the funds rate target.

The chart shows daily data since January 2007 of the effective federal funds rate, the FOMC's funds rate target, and the 4-week secondary market T-bill rate-as well as the New York Fed's effective OMOs for the maintenance period (a 14-day period in which bank reserves are measured). To measure the effect that OMOs have on bank reserves and therefore the federal funds rate, I calculate the OMO maintenance-period effect, which is the sum of all securities purchased or sold by the New York Fed on a given day, each of which are multiplied by their own maturity; the sum is then divided by 14-the number of days in the reserve maintenance period. The resulting value indicates the cumulative effect that one day's OMOs has on bank reserves over the entire maintenance period.

Although the funds rate target was 5.25 percent on August 9, the chart shows that the effective funds rate was 5.41 percent, even though the Fed increased the supply of reserves by purchasing $\$ 24$ billion in assets on that day. Because $\$ 12$ billion of these transactions had a 14-day maturity, while the other $\$ 12$ billion had an overnight maturity, the OMO maintenance-period effect of these purchases was $\$ 12.86$ billion. The next day, the Fed purchased $\$ 38$ billion in assets, with an effect of $\$ 8.14$ billion. The funds rate averaged 4.68 percent, significantly below the FOMC's target. The chart shows that, although these transactions are large, they are not particularly unusual relative to the size of OMOs made during the year. In sum, the funds rate was above the target on August 9, despite an apparent attempt by the Fed to lower the rate by adding reserves. ${ }^{1}$ The funds rate was below the target the next day, despite a relatively smaller purchase of reserves. Moreover, the funds rate remained below the target through the remainder of August. These facts suggest the possibility that the behavior of the funds rate is not particularly affected by daily OMOs.

What did change in the wake of the developments in the subprime mortgage market is a sharp rise in the short-term liquidity premium. Specifically, the rates on short-term T-bills declined significantly relative to other short-term rates, apparently due to a "flight to quality." The 4 -week T-bill rate declined to 4.28 percent on August 10 and declined further to a low of 2.35 percent on August 20 before rising. T-bills and federal funds are very good substitutes for meeting the liquidity needs of depository institutions. Hence, one possibility is that the flight to quality pulled the funds rate down from the FOMC's target. In contrast, rates on longer-term sources of funding for depository institutions rose: 1-month secondary-market certificates of deposit and 1-month eurodollar deposits both rose about 25 basis points on August 9 and remained about 30 to 40 basis points above their pre-August 9 levels through the end of the month. Rates that are not closely linked to depository institutions' liquidity or funding needs, such as prime financial and nonfinancial commercial paper, were essentially unaffected by developments in the subprime mortgage market.

${ }^{1}$ However, this is the largest two-day injection of effective reserves for 2007, $\$ 10.5$ billion. The next largest, $\$ 9.33$ billion, was for the two days ending February 23 .

Views expressed do not necessarily reflect official positions of the Federal Reserve System.

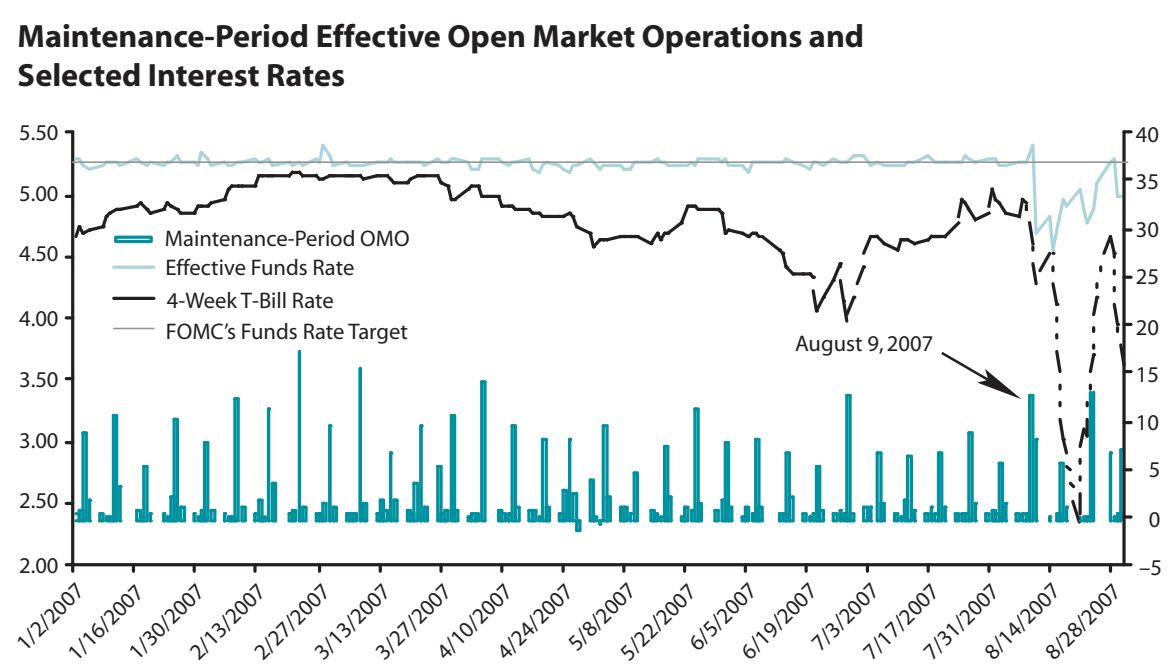

